\title{
The Enigmatic Eosinophil: Investigation of the Biological Role of Eosinophils in Parasitic Helmint Infection
}

\author{
Karen S Ovington ${ }^{+}$, Carolyn A Behm \\ Division of Biochemistry and Molecular Biology, Faculty of Science, The Australian National University, \\ Canberra, ACT0200, Australia
}

In many helminth infected hosts the number of eosinophils increases dramatically, often without any concurrent increases in the number of other leukocytes, so that eosinophils become the dominant cell type. Many experimental investigations have shown that the eosinophilia is induced by interleukin-5 (IL-5) but its functional significance remains unclear. Mice genetically deficient in IL-5 (IL-5-/-) have been used to evaluate the functional consequences of the IL-5 dependent eosinophilia in helminth infected hosts. Host pathology and level of infection were determined in IL-5-/- and wild type mice infected with a range of species representative of each major group of helminths. The effects of IL-5 deficiency were very heterogeneous. Of the six species of helminth examined, IL-5 dependent immune responses had no detectable effect in infections with three species, namely the cestodes Mesocestoides corti and Hymenolepis diminuta and the trematode Fasciola hepatica. In contrast, IL-5 dependent immune responses were functionally important in mice infected with three species, notably all nematodes. Damage to the lungs caused by migrating larvae of Toxocara canis was reduced in IL-5-/- mice.

Infections of the intestine by adult stages of either Strongyloides ratti or Heligmosomoides polygyrus were more severe in IL-5-/- mice. Adult intestinal nematodes were clearly deleteriously affected by IL5 dependent processes since in its presence there were fewer worms which had reduced fecundity and longevity. The implications of these results for the viability of using inhibitors of IL-5 as a therapy for asthma are considered.

Key words: eosinophil - interleukin-5 - interleukin-5 deficient mice - helminth - asthma

Eosinophils are non-dividing cells that arise in the bone marrow and then are released into the bloodstream where they typically make up only 2$5 \%$ of circulating leukocytes (Wardlaw \& Moqbel 1992). In a fairly narrow range of conditions, notably in allergic states and following infection with multicellular parasites (helminths), the number of eosinophils increases dramatically. Eosinophil proliferation occurs without any concurrent increases in the number of other leukocytes so that eosinophils can become the dominant leukocyte (Dent et al. 1990, Sanderson 1991). The cytokine interleukin-5 (IL-5) is the major factor necessary for proliferation and activation of eosinophils in vivo (Sanderson 1992).

The cytoplasmic granules that are stained by eosin are the main distinguishing feature of eosinophils. These granules contain numerous cytotoxic

\footnotetext{
Financial support: The Australian Research Council and National Health and Medical Research Council.

${ }^{+}$Corresponding author. Fax +61-2- 6249.0313. E-mail: Karen.Ovington@anu.edu.au Received 3 September 1997

Accepted 30 September 1997
}

proteins as well as pro- and anti-inflammatory mediators. Much of the pathology of asthma appears to be a consequence of inappropriate proliferation, activation and degranulation of eosinophils in the lungs (Desreumaux \& Capron 1996, Foster et al. 1996, Martin et al. 1996). There is considerable hope that the pathology of asthma can be limited by treatments that inhibit IL-5. However, a number of observations suggest that IL-5, and the eosinophils it induces, are of fundamental biological importance. First, the sequence of IL-5 has been highly conserved among mammals (Sanderson 1994) and eosinophils or eosinophil-like cells are present in most vertebrates (Jones 1993). Second, IL-5 is an unusual cytokine as in vivo it appears to have an extremely narrow range of actions and other cytokines cannot fully compensate for its absence (Dent et al. 1990). Third, it is energetically demanding to mount an eosinophilia. As an eosinophilia characterises infection by helminths, it has long been thought that eosinophils kill helminths and that this is their raison d'être.

THE ROLE OF EOSINOPHILS IN HELMINTH INFECTION

Helminths are multicellular parasites that are morphologically and functionally diverse, ranging from tapeworms (cestodes), to leaf-shaped flukes 
(trematodes), spiny-headed worms (acanthocephalans) and the very common roundworms (nematodes). Infection of mammalian hosts with helminths, but not unicellular organisms, typically induces a Th2 type cytokine response that results in IL-4-induced elevations in IgE and intestinal mastocytosis as well as an IL-5-induced proliferation and activation of eosinophils. The biological functions of IL- 4 have been well characterised but those of IL-5, and the eosinophils it induces, are still poorly resolved. Helminths are distinguished from other parasites and infectious agents by their large size. Since their size precludes phagocytosis, they must be destroyed in other ways. Eosinophils, with their many cytoplasmic granules containing a battery of toxic molecules that can be released extracellularly in response to antigenic stimuli, theoretically appear to be an appropriate form of defence against helminths.

Despite many experimental investigations, the role of eosinophils in helminth infections remains controversial; they may be involved in killing helminths, and they have also been linked very strongly to host pathology. It is well established that eosinophils migrate into tissues parasitised by helminths. In vitro, eosinophils adhere to a variety of helminth larvae coated with immunoglobulins; they release the contents of their granules and secrete soluble factors which kill the larvae (Butterworth et al. 1984, Hagan et al. 1985a, Medina de la Garza et al. 1990, Brattig et al. 1991, Johnson et al. 1991). In vivo, however, the situation is unclear. Eosinophils accumulate and degranulate around tissue-invading helminth larvae, and are numerous in granulomatous areas surrounding dead helminth larvae (Moqbel 1980, Lange et al. 1994). Eosinophil-derived proteins have also been demonstrated on the surfaces of dead and live larvae (Ackerman et al. 1990), but whether eosinophils are directly responsible for effecting the death of helminth larvae in vivo is not proven in most cases, with the possible exception of the filarial nematode Onchocerca lienalis (Folkard et al. 1996). Epidemiological evidence supporting a role in protection against schistosomiasis, a trematode infection, has been obtained for human populations (Sturrock et al. 1983, Hagan et al. 1985b). Studies in which mice were pretreated with monoclonal antibodies to IL-5 before helminth infection have shown that eosinophilia did not develop; in most cases this treatment had no effect on the progress of the infection. However in two cases, primary infections of mice with the nematodes Angiostrongylus cantonensis or Strongyloides venezuelensis, ablation of eosinophils using antiIL-5 monoclonal antibodies increased the survival and distribution of the parasites in certain tissues
(Korenaga et al. 1991, 1994, 1995, Sasaki et al. 1993). Resistance of mice to secondary infections was also compromised by anti-IL-5 monoclonal antibody treatment in murine infections of two filarial nematodes, $O$. volvulus (a parasite of humans) and $O$. lienalis (a parasite of cattle) (Lange et al. 1994, Folkard et al. 1996). Using monoclonal antibodies to IL-5 to prevent eosinophilia in hosts is a useful tool but the presence of foreign antibodies could have additional, artifactual, effects on the host's immune responses, such as stimulating other immune cells.

\section{MICE GENETICALLY DEFICIENT IN INTERLEUKIN-5}

Interleukin-5 deficient mice (IL-5-/-) have been produced by homologous recombination between the IL-5 gene in mice embryonic stem cells and a mutant gene construct which had the neomycin resistance gene inserted into exon 3 in a codon essential for IL-5 function (Kopf et al. 1996). The phenotype of IL-5-/- mice has only been partially characterized. As expected, the most obvious and clear-cut abnormalities detected in IL-5-/- mice were fewer eosinophils before infection with helminths and an inability to generate the eosinophilia normally associated with helminth infection. The only other significant abnormality reported to date in IL-5-/- mice is delayed development of a population of $\mathrm{CD}^{+} \mathrm{B}$ cells known as B-1 cells. In 2week-old mice IL-5 deficiency resulted in a 50$80 \%$ reduction in the percentage of B-1 cells in the peritoneal cavity. By 6-8 weeks of age the B-1 cell populations of IL-5-/- and wild type mice (IL-5+/+) were similar. Our subsequent studies have, however, shown a significant life-long impairment of B-1 cells and B-1 cell responses in IL-5-/- mice (Ovington, Morgan, Matthaei, Young \& Behm, unpublished results). This agrees with observations on IL-5 receptor alpha chain-deficient mice (IL5R-/-) which have recently been developed (Yoshida et al. 1996). As well as impaired eosinophilopoiesis, IL-5R-/- mice were found to have proportionally fewer peritoneal B-1 cells and impaired responsiveness to T-independent antigens. In addition, and perhaps at least partially reflecting reduced numbers and function of B-1 cells, IL-5 R-/- mice had low serum concentration of IgM and IgG3. Thus overall it appears that the major abnormalities of mice unable to produce a functional IL-5 or its receptor may be restricted to eosinophils, B-1 cells and some antibodies. It must be noted, however, that the immune responses of these genetically modified mice have not yet been adequately characterised following infection with helminths. Nevertheless, these mice are excellent tools to use to evaluate the roles that IL-5 and eosinophils play in helminth infected hosts. 

OUTCOMES OF HELMINTH INFECTION IN
INTERLEUKIN-5 DEFICIENT MICE

In our studies we have infected mice genetically deficient in IL-5 with a range of species representative of each of the major groups of helminths and then quantified the level of helminth infection and, for some species, host pathology (see Table I). These experiments have shown that whilst eosinophilia induced by helminth infections is dependent on IL-5, some eosinophils are IL-5-independent. In addition, we have shown that IL-5-dependent immune responses severely curtail some, but not all, helminth infections.

\section{IL-5-DEPENDENT EOSINOPHILIA}

The ability of IL-5-/- mice to mount an eosinophilia in response to infection by helminths was significantly impaired (Kopf et al. 1996, Takamoto et al. 1997). This occurred for all species of helminth tested and at all sites in the body that were examined, including the bone marrow, peripheral blood, peritoneal cavity, skeletal muscle, lungs and intestine. Failure of IL-5-/- mice to mount a normal helminth-induced eosinophilia does not appear to be due to abnormalities of cells in the bone marrow. When cells from the bone marrow of IL-5-/mice were incubated with IL-5 plus IL-3 and granulocyte macrophage colony stimulating factor in vitro, their capacity to differentiate into eosinophils was equivalent to that of cells from IL-5+/+ mice (Takamoto et al. 1997).

\section{IL-5-INDEPENDENT EOSINOPHILS}

Eosinophils are present but in considerably reduced numbers in IL-5-/- mice (Kopf et al. 1996). These eosinophils, which must arise independently of IL-5, are referred to as IL-5-independent eosinophils. The bone marrow and intestinal mucosa contain 30-50\% fewer eosinophils in the absence of IL-5 (Ovington, Morgan, Matthaei, Young \& Behm, unpublished results). Although there was no increase in the number of bone marrow eosinophils in response to helminth infection in IL-5-/mice, we detected a significant decrease in the number of eosinophils in the bone marrow of IL-5-/mice following some, but not all, helminth infections. For example, on days 7 and 14 post-infection (pi) with Toxocara canis there were significantly fewer eosinophils in the bone marrow of IL-5-/- mice than before infection, indicating that in helminth-infected hosts IL-5 is not essential for IL-5-independent eosinophils to move out of the bone marrow (Takamoto et al. 1997). Somewhat unexpectedly, we detected a relatively small but highly statistically significant tissue eosinophilia in IL-5-/- mice at the site of all helminth infections (liver, intestine, lungs and peritoneal cavity). Thus, for example, in the region of the small intestine parasitised by Strongyloides ratti, there was about a 15-fold increase in the number of eosinophils for IL $5+/+$ mice and a 3 -fold increase in the number for IL-5-/- mice (Ovington, McKie, Matthaei, Young \& Behm, manuscript in preparation). This clearly illustrates that IL-5-independent eosinophils, at least, do not require IL-5 to move into sites of helminth infection. The limited eosinophilia at the sites of helminth infection in IL-5-/- mice is most probably a consequence of redistribution of IL-5-independent eosinophils present in the tissues, but it could also arise because of a combination of limited eosinophilopoiesis in bone marrow and equivalent movement of eosinophils from bone marrow to infection sites.

IL-5-independent eosinophils localised at helminth-infected sites appeared morphologically similar to IL-5-dependent eosinophils (Takamoto et al. 1997). The IL-5-independent eosinophils also appeared to degranulate in the vicinity of helminths because crystals, thought to be Charcot-Leyden crystals, were present in the lungs of IL-5-/mice infected with $T$. canis. Since IL-5-independent eosinophils are granular and have the capac-

\section{TABLE I}

The effects of a genetic deficiency of IL-5 on primary infections with a range of species of helminths

\begin{tabular}{llcc}
\hline Group of helminth & Species of helminth & \multicolumn{1}{c}{ Effect of IL-5 deficiency } \\
\cline { 3 - 3 } Nematode & Strongyloides ratti & Level of Infection & Host pathology \\
& Heligmosomoides polygyrus & & nd \\
& Toxocara canis & 0 & nd \\
Cestode & Hymenolepis diminuta & 0 & 0 \\
Mesocestoides corti & 0 & 0 \\
\hline
\end{tabular}

represents a significant increase, represents a significant decrease, 0 indicates no effect was detected, nd — not determined. 
ity to localise at sites of helminth infection and degranulate, they may be functionally significant (Table II).

\section{TABLE II}

The characteristics of IL-5-independent eosinophils identified from studies of helminth infection in mice genetically unable to produce a functional IL-5

Characteristics of IL-5-independent eosinophils

- present in the bone marrow and other tissues

- morphologically similar to IL-5-dependent eosinophils

— much less abundant than IL-5-dependent eosinophils

- leave the bone marrow in response to helminth infection

— localise to helminth-infected tissue in a wide range of sites

— accumulate at sites of helminth infection

— can degranulate in the vicinity of helminths in tissues

HELMINTH INFECTIONS IN WHICH IL-5-DEPENDENT IMMUNE RESPONSES APPEAR TO BE UNIMPORTANT

Many of the species of helminth that we have tested and the host pathology they induce are not affected by IL-5-dependent immune responses.

(i) the trematode Fasciola hepatica - The common liver fluke, $F$. hepatica, uses a wide range of mammals including ruminants, rodents, marsupials and humans as its definitive host (host in which adult parasites live) and aquatic snails as its intermediate host. In snails $F$. hepatica undergoes several rounds of asexual reproduction to form cercariae which burst out of snails and swim until they reach vegetation on which they encyst to form metacercariae. Mammals become infected by ingesting metacercariae that release juvenile flukes in the small intestine. Juvenile flukes penetrate the wall of the small intestine then move through the peritoneal cavity to the liver where, over the next few weeks, they cause considerable damage by migrating through the liver tissues en route to the bile duct. Only a small proportion of metacercariae give rise to juvenile flukes which reach the bile duct and develop into adults. A marked eosinophilia develops in the peritoneal cavity, liver and peripheral blood of rodents infected with $F$. hepatica (Milbourne \& Howell 1990, Charbon et al. 1991, Smith et al. 1992). It has been suggested that flukes themselves release a molecule with IL-5like activity (Milbourne \& Howell 1993, in press). Many studies have implicated eosinophils and the reactive oxygen intermediates they release as be- ing important in killing of juvenile flukes in both primary and secondary infections (Doy et al. 1980, Davies \& Goose 1981, Burden et al. 1983, Callahan et al. 1988, Smith et al. 1992). It is also possible that the large number of eosinophils which migrate to the liver either contribute to, or limit, tissue damage caused by migrating juveniles.

Following a primary infection with 2-5 metacercariae we found that IL-5+/+ and IL-5-/- mice had similar levels of infection and sustained equally substantial liver damage (McRandle et al. manuscript in preparation). In mice experiencing a primary infection with $F$. hepatica, IL-5-dependent immune responses do not therefore prevent juvenile flukes from reaching the bile duct or contribute to host pathology. Although eosinophils do not influence the infection in mice, they are not precluded from an effect in hosts, such as rats, which develop age resistance to primary F. hepatica infections. Mice lacking IL-5 did not develop a significant peripheral blood eosinophilia following prolonged, heavy infection, which suggests that flukes do not produce an IL-5 like molecule. Mice are inadequate hosts to use to examine the role of IL-5 in secondary infections of $F$. hepatica: they tolerate the infection poorly and unlike other hosts, such as rats and cattle, do not develop resistance to re-infection (Haroun \& Hillyer 1986).

(ii) the adult cestode Hymenolepis diminuta In immunologically-naive hosts, eosinophils are relatively rare in most tissues but are present in considerable numbers in intestinal tissues. We hypothesised that IL-5 and eosinophils may be components of innate, intestinal immune responses that dictate host susceptibility to particular species of helminth. The cestode, $H$. diminuta, which can develop to maturity in rats and humans, but not mice (Hopkins et al. 1972), was used to test this hypothesis. This tapeworm appears to be extremely well-adapted to survive in the intestine of rats as it persists for long periods of time without causing any notable host pathology. Indeed, the life-span of $H$. diminuta in rats is greater than that of its hosts (Read 1967). Definitive hosts become infected with $H$. diminuta by ingesting cysticercoids found in the body cavity of insect intermediate hosts. Cysticercoids evaginate in the lumen of the small intestine to form tapeworms that grow rapidly. In mice some of the cysticercoids develop into small worms but these do not mature and are rapidly expelled by host immune responses. Groups of IL$5+/+$ and IL-5-/- mice were each orally infected with five cysticercoids. The absence of IL-5 did not prolong survival or improve the growth rate of H. diminuta. Thus for this species of helminth, IL5-dependent immune responses are not a critical determinant of host susceptibility. 
(iii) The larval cestode Mesocestoides corti - $M$. corti is the quintessential laboratory parasite that has routinely been used by immunologists studying IL5 , eosinophils and other immune responses to helminths (e.g. Pollacco et al. 1978, Cook et al. 1988, Dent et al. 1990). Carnivores, which are the definitive host for $M$. corti, become infected by eating intermediate hosts - a wide range of vertebrates, including reptiles, birds, rats and mice - infected with larval stages known as tetrathyridia. In the carnivore gut, the tetrathyridia develop into adult worms which reproduce both sexually and asexually and release eggs which pass out in the faeces. The next stage of the life cycle is uncertain: the eggs are thought to be ingested by soil arthropods which are later ingested by vertebrate intermediate hosts. The resulting tetrathyridia inhabit the peritoneal cavity and liver where they reproduce asexually. This parasite is particularly amenable to experimentation as it can be repeatedly passaged by simply isolating tetrathyridia from the peritoneal cavity of an infected mouse and injecting them directly into the peritoneal cavities of uninfected mice. Since this culture method bypasses several stages in the life cycle, it should be noted that laboratory strains of $M$. corti which have been cultured for innumerable generations, without selection through the other hosts in the life cycle, may be biologically substantially different from the parasite originally isolated in 1965 (Specht \& Voge 1965).

The species is of immunological interest, though, as the outcome of infection differs in rats and mice which both mount a large eosinophilia in response to the infection (Pollacco et al. 1978, Chernin \& McLaren 1983). In the peritoneal cavity and liver of rats the reproduction of $M$. corti is limited by immune responses, whereas in mice host immune responses are ineffective, so the parasites replicate unchecked and the hosts eventually die. It has been hypothesised that toxic products released from eosinophils could damage other immune cells resulting in immunosuppression. We used IL-5-/- mice to determine if IL-5 and/or eosinophils are immunosuppressive and/or exacerbate $M$. corti infection (Milbourne, Ovington, Matthaei, Young \& Behm, manuscript in preparation). IL-5+/+ and IL-5-/- mice were given intraperitoneal injections of 20 tetrathyridia of $M$. corti and asexual reproduction of the parasite was monitored for up to four months. Absence of IL-5 and IL-5-dependent eosinophils had no significant effect on asexual reproduction of $M$. corti or on host pathology.

NEMATODE INFECTIONS IN WHICH INTERLEUKIN-5 IS FUNCTIONALLY IMPORTANT

Of the six species of helminths that we have examined, IL-5-dependent immune responses were found to be functionally important in mice infected with three species, notably all nematodes (Table I). We examined three nematode species, all natural parasites of mice, that differ in biological aspects of their life cycle, namely (i) T. canis which does not reach maturity in mice; (ii) $S$. ratti which develops an acute intestinal infection lasting up to 10 days; and (iii) Heligmosomoides polygyrus which develops a chronic intestinal infection lasting several months.

(i) Toxocara canis - T. canis is primarily a parasite of dogs but is also a significant problem in humans worldwide. It has a very complex life cycle. If mature dogs ingest embryonated eggs, the larvae that hatch from them penetrate the gut, wander through the body and eventually become dormant in body tissues. If the dog is female and becomes pregnant the larvae become activated, enter the circulation and infect the developing foetuses via the placenta. In lactating bitches and puppies, larvae migrate from the gut to the lungs and then by way of the trachea into the intestine where they develop into adults which release eggs. If humans or rodents ingest eggs, larvae migrate through tissues causing visceral larval migrans but do not develop beyond early larval stages. If dogs eat infected rodents they can become infected. Mice thus act as 'paratenic' hosts for T. canis. In humans, infection is dead-end but inflammatory responses to larvae, which include a massive and persistent eosinophilia, cause considerable pathology. The larvae often become trapped in the eye and can cause permanent blindness.

The role of IL-5-dependent immune responses in $T$. canis infection is of interest as the species induces a particularly large systemic eosinophilia (Kayes \& Oaks 1980, Sugane \& Oshima 1980) and it was thought that, like $F$. hepatica, larvae of $T$. canis may produce molecules that are recognised by the host as IL-5. This possibility arose because the main peak of eosinophilia induced in mice during larval migration is not altered by absence of a thymus (Sugane \& Oshima 1982, Kusama et al. 1995 ) and although thymic independent $\mathrm{CD} 4^{-} \mathrm{CD} 8^{-}$ T-cells can produce IL-5, their capacity to do so is much less than that of equivalent cells from mice with a thymus (Takamoto et al. 1995).

We infected IL-5+/+ and IL-5-/- mice with embryonated eggs of $T$. canis and quantified the levels of eosinophilia, infection and damage to the lungs (Takamoto et al. 1997). The eosinophilia in infected tissues of IL-5-/- mice was comparable with that seen in other helminth infections examined in these mice. This IL-5-independent eosinophilia does not appear to be due to excretory/secretory products of the larvae since in vitro these prod- 
ucts failed to stimulate bone marrow cells from either IL-5+/+ or IL-5-/- mice to differentiate into eosinophils. Thus larvae of T. canis therefore probably do not produce an IL-5-like molecule. The number and distribution of larvae of T. canis were similar in IL-5+/+ and IL-5-/- mice, indicating that the massive IL-5-dependent eosinophilia and other IL-5-dependent immune responses do not limit primary infection in mice. Damage to the lungs caused by the migrating larvae of $T$. canis appeared to correlate with the extent of infiltration by eosinophils and was accordingly considerably reduced in IL-5-/- mice. Thus, in paratenic hosts, migrating larvae of $T$. canis induce hosts to produce IL-5 resulting in a massive eosinophilia that has no apparent effect on the larvae but is deleterious to the host.

(ii) Strongyloides ratti - S. ratti, a nematode that is a natural parasite of rats and mice, belongs to the order Rhabditata which includes species that have, on an evolutionary time scale, only recently embraced parasitism as a way of life (Roberts \& Janovy 1996). Like other members of this order $S$. ratti can have parasitic or, for some generations at least, entirely free-living life cycles. In rats and mice, adult nematodes, which are all female, feed on intestinal mucosa and release eggs that pass out in faeces. Soon after being laid, eggs hatch to release larvae that can infect hosts or enter a freeliving life cycle. In the free-living life cycle, larvae develop into adult male and female worms that live in the soil. These worms reproduce sexually to produce eggs that hatch to release larvae. These larvae can repeat the cycle in the soil or infect a host. Larvae infect hosts by skin penetration after which they migrate extensively through many sites in the body including the cranial cavity and the lungs (Dawkins \& Grove 1981, 1982). Less than half of the larvae that penetrate eventually reach the intestine and become egg-producing adults.

In both rats and mice, the infection is shortlived as host immune responses lead to the expulsion of intestinal worms (Moqbel \& Denham 1977, Moqbel 1980, Dawkins \& Grove 1981). Helminths that are considered to be well-adapted to their hosts typically cause little host pathology and result in chronic infections. The observations that $S$. ratti can be free-living, has a complex migration route that results in considerable pathology, and is rapidly expelled, support the notion that this species has only 'recently' become parasitic. Eosinophilia and other IL-5-dependent immune responses may be important in limiting helminths when they first, by chance, associate with vertebrates. With prolonged exposure to hosts, helminths not susceptible to host immune responses would be selected.
Therefore, we hypothesised that less well-adapted parasites such as $S$. ratti are more likely to be limited by IL-5/eosinophils than helminths that are better adapted to their hosts.

Groups of IL-5-/- and IL-5+/+ mice were infected with a range of doses of larvae of $S$. ratti (Ovington, McKie, Matthaei, Young \& Behm, manuscript in preparation). In the absence of IL-5, $S$. ratti was clearly much more successful because, although infection was not prolonged, about four times as many eggs and larvae were released into the faeces (Table III). The increased reproduction of $S$. ratti in IL-5-/- mice was due to a greater number of intestinal worms that were, on average, more fecund. Typically in helminth infections there are density-dependent constraints on worm fecundity (Keymer 1982). If worm burdens are greater, the average fecundity of individual worms is reduced. Our experiments have shown that in $S$. ratti infection in mice higher intestinal worm densities do not limit fecundity in the absence of IL-5. Mice previously infected with $S$. ratti were resistant to reinfection whether or not they had IL-5. Thus IL5 plays a critical role in limiting primary but not secondary infections of $S$. ratti in mice.

A temporary weight loss often occurs in mice infected with heavier doses of $S$. ratti. In the absence of IL-5, mice lost more weight as a consequence of $S$. ratti infection and it took longer for them to regain this weight (Ovington, McKie, Matthaei, Young \& Behm, manuscript in preparation). This may simply reflect our observations that IL-5-/- mice were more severely affected as they harboured more intestinal worms. It could also indicate that IL-5-dependent immune responses are important, but not essential, for tissue repair and/ or down-regulation of immune responses.

(iii) Heligmosomoides polygyrus - H. polygyrus has a simple life cycle, with mice being the definitive host. If infective larvae are swallowed by mice, they infect the intestinal mucosa where they develop into adults within about seven days. The adult worms then move into the lumen of the small intestine and begin egg production that continues for many months. Larvae infective to mice develop from eggs passed out in faeces. H. polygyrus is a natural parasite of mice and is representative of the majority of intestinal parasite nematodes as it does not have an alternative free-living life cycle and causes chronic infections with little pathology (Monroy \& Enriquez 1992). On the basis of earlier reports it has been generally assumed that IL5 does not regulate primary infections of $H$. polygyrus (Urban et al. 1991). However, it has been shown that the levels of IL-5 and IL-9 mRNA are increased within $6 \mathrm{hr}$ of primary infection with $H$. 
TABLE III

Comparison of Strongyloides ratti infection in female wild type (IL-5+/+) and IL-5-deficient C57B1/6 mice (IL-5-/) following infection with 1000 infective larvae. Duration of the infection was not altered by IL-5 deficiency (Ovington, McKie, Matthaei, Young \& Behm, manuscript in preparation)

\begin{tabular}{lc}
\hline Parameter & Ratio of values for $\frac{\text { IL-5-/- mice }}{$\cline { 2 - 2 }} \\
\hline Number of adult worms in the intestine at 6 days post-infection & 1.5 \\
Number of eggs and larvae released into the faeces on day 5 post-infection & 2.5 \\
Worm fecundity (eggs and larvae/worm) at day 5 post-infection & 1.7 \\
Total number of eggs and larvae released into the faeces over the course of infection & 4.4 \\
\hline
\end{tabular}

TABLE IV

Comparison of Heligmosomoides polygyrus infection in female wild type (IL-5+/+) and IL-5-deficient C57B1/6 mice (IL-5-/-) following infection with 200 infective larvae (Ovington, Morgan, Matthaei, Young \& Behm, unpublished results)

\begin{tabular}{lc}
\hline Parameter & Ratio of values for IL-5-/- mice \\
\cline { 2 - 2 } & IL-5+/+ mice \\
\hline Number of adult worms in the intestine at week 3 post-infection & 1.8 \\
Number of eggs released into the faeces/24hr at weeks 3 post-infection & 2.3 \\
Worm fecundity (eggs/worm) at week 3 post-infection & 2.3 \\
Patency (weeks) & $>1.8$ \\
Total number of eggs released into the faeces over the course of infection & 4.4 \\
\hline
\end{tabular}

polygyrus; thus these cytokines are probably the first ones produced in this infection (Svetic et al. 1993).

In the absence of IL-5, mice given a primary infection of $H$. polygyrus had more intestinal worms that were more fecund and persisted in the intestine for many weeks longer (Table IV; Ovington, Morgan, Matthaei, Young \& Behm, unpublished results). The combination of these three factors resulted in a four fold increase in the total number of eggs released over the course of the infection. Resistance to reinfection was not impaired by IL-5 deficiency.

\section{OVERVIEW}

We have shown in the experiments discussed above that the effects of IL-5 on helminth infections are very heterogeneous (Table V). Many more species of helminth should be examined to clarify the reasons for this heterogeneity. The level of infection was only limited by IL-5-dependent immune responses in two of the six species of helminth examined. The degree of parasite/host adaptation does not correlate with susceptibility to IL5 -mediated immune responses since of these two species, one (H. polygyrus) can be considered well- adapted whilst the other ( $S$. ratti) is thought to be less well-adapted. These two species differ from the other species examined because they are intestinal nematodes that use the mouse as a definitive host (i.e. the host in which sexual reproduction

\section{TABLE V}

Summary of the effects of a genetic deficiency of IL-5 in helminth infections of mice

Effect of genetic IL-5 deficiency
— many fewer eosinophils in uninfected mice
— no detectable eosinophilia in the bone marrow in
response to helminth infection
— considerably reduced tissue eosinophilia at the sites
of helminth infection
— exacerbation of primary infection with intestinal
nematodes in the definitive host
- increased pathology in the definitive host in primary
infections with one species of intestinal nematode
(Strongyloides ratti)
reduced pathology in the intermediate host in primary
infection with a tissue-dwelling nematode (Toxocara
canis)


takes place). For all the other helminths examined, mice serve either as intermediate or paratenic hosts (M. corti, T. canis), or act as a host in which the helminth cannot develop to maturity (H. diminuta), or are not in the intestine as adults ( $F$. hepatica). For these species we have shown that IL-5-dependent immune responses are ineffective against juvenile stages but the possibility remains that they limit adult stages (which cannot be tested in mice). In the intestinal nematode infections, however, adult worms were clearly deleteriously affected by IL-5 since in its presence their fecundity and/or longevity were reduced. The increased number of intestinal nematodes in IL-5 deficient mice may have arisen because IL-5-dependent immune responses were effective against adult intestinal nematodes and/or the larval stages. Further work is necessary to determine at what stage of nematode development IL-5-dependent immune responses act to limit intestinal worm burdens.

Adults of the two species of nematode for which IL-5 has been shown to be inhibitory are parasites in the intestine. Eosinophils are present in considerable numbers in the intestine of naive hosts but are relatively rare elsewhere in the body. Induction of the proliferation and activation of eosinophils may be the mechanism by which IL-5 limits intestinal nematode infections but other cell types such as B-1 cells could also be involved. B-1 cells are predominantly located in the peritoneal cavity from which they move to the intestinal mucosa (Hardy \& Hayakawa 1986, Herzenberg et al. 1986, Beagley et al. 1995, Murakami \& Honjo 1995). The gut-associated lymphoid tissue (GALT) is thought to include 'modern' and 'primitive' components (Murakami \& Honjo 1995). The 'modern' components include $\alpha \beta \mathrm{T}$ cells and conventional B cells, which arise in the thymus and bone marrow respectively and mediate immune responses with high specificity. The 'primitive' components include $\gamma \delta$ T cells and B- 1 cells and result in less specific responses. The 'primitive' components of the GALT are thought to lead to immediate responses deleterious to bacteria in the intestine (Murakami $\&$ Honjo 1995). Since the intestines and gills of earliest chordates were probably also attacked by helminths (Clemmey 1976, Bryant 1982), the 'primitive' arm of the GALT may also have evolved as a rapid 'front-line' response to limit helminth infection. There are proportionally fewer B-1 cells in mice genetically deficient in IL-5 or its receptor. Whilst the function of B-1 cells in helminthinfected hosts is unknown, a Th2 type environment characteristic of helminth-infected hosts facilitates the differentiation of mature B-1 cells into B/macrophage cells (Borrello \& Phipps 1996). The phagocytic $\mathrm{B} /$ macrophage cells are thought to act as antigen-presenting cells and to be an important component of the intestinal defence mechanism in diseases which induce Th2 type responses (Borrello \& Phipps 1996). Primary infections by intestinal nematodes may therefore be limited by IL-5 through its effects on B-1 and B/macrophages.

Interleukin-5 and the considerable eosinophilia it induces had no detectable effect on most of the species of helminth examined in these studies. Although the IL-5-independent eosinophils that accumulated in all parasitised tissues appeared morphologically and functionally similar to IL-5-dependent eosinophils, we have no evidence that they were helminthicidal in any of the infections. Such a result could be interpreted in two ways: (i) the helminthicidal activity of IL-5-independent eosinophils is often sufficient on its own to limit helminth infection and there is no incremental killing due to IL-5-dependent eosinophils; or, more probably, (ii) larval stages of some helminths are not harmed by the many IL-5-dependent (or -independent) eosinophils that surround them. In the lungs of mice infected with $T$. canis, damage to host tissues was increased in the presence of IL-5, which suggests that IL-5-dependent eosinophils were degranulating in response to larvae of this species (Takamoto et al. 1997). Thus IL-5 and eosinophils induced by helminth larvae can be deleterious to the host. In the other infections in which IL-5 was not helminthicidal, the presence of IL-5 had no detectable effect on host pathology, suggesting that the many IL-5-dependent eosinophils were not degranulating. Thus IL-5+/+ mice infected with some helminths such as $M$. corti or $F$. hepatica could be considered similar to those transgenic mice with multiple copies of the IL-5 gene that are constitutively expressed. These transgenic mice have a persistently high eosinophilia (Dent et al. 1990, Tominaga et al. 1991) but no apparent pathology and are highly resistant to primary helminth infections (Dent, this issue). Therefore, although in normal mice a considerable IL-5-dependent eosinophilia is not detrimental to the tissuedwelling larval stages of the helminths that induce it, the eosinophilia could be of significance because it might limit infection by other incoming, and thus competing, species of helminth.

The pathological consequences of helminth infection normally increase with worm burden. The increased pathology observed in IL-5-/- mice infected with $S$. ratti is at least partly because they harbour more worms. At a population level, IL-5 may have highly significant effects on helminthinduced pathology. In our experiments IL-5-/- mice infected with intestinal nematodes released four to five times as many infective stages in their faeces as IL-5+/+ mice. In the field, increased production 
of infective stages would increase levels of infection both directly by facilitating auto-infection and indirectly by increasing environmental contamination and hence exposure to infective stages.

\section{INTERACTIONS BETWEEN HELMINTH INFECTION AND ALLERGIC INFLAMMATION}

Infection with helminths and allergic inflammation/asthma induce very similar immune responses; both conditions are characterised by a predominance of Th2 type responses with the resulting proliferation and activation of eosinophils and the elevation of $\operatorname{IgE}$ (Robinson et al. 1992, Tagboto 1995, Coyle et al. 1996, Konno et al. 1996). Epidemiological studies have attempted to make a causal link between helminth infection and the atopic/asthmatic state. The results of these studies have been highly variable and appear to be contradictory; it has been variously hypothesised that (i) helminth infection induces asthma; (ii) helminth infection protects against asthma; and (iii) asthma protects against helminth infection (see Pritchard 1992 for review). Interpretation of epidemiological studies is clearly problematic since the relative timing and extent of exposure to both allergens and helminths are unknown but likely to be highly variable. Our studies using IL-5-/- mice have shown that helminths are very heterogeneous in their susceptibility to IL-5-dependent immune responses. The type and number of helminths, their developmental stages and location in the body may all influence interactions between helminths and the induction of allergic inflammation in the lungs. A variety of mechanisms, involving or independent of IL-5, could explain the three ways noted above in which asthma and helminth infections have been causally linked.

\section{VIABILITY OF USING INHIBITORS OF IL-5 AS A THERAPY FOR ASTHMA}

Our experiments using mice genetically deficient in IL-5 have clearly shown that IL-5 is very important in limiting some murine helminth infections. If this is also the case in humans, there is the possibility that anti-IL-5 treatment of asthmatics could exacerbate at least some helminth infections. The mechanisms by which IL- 5 controls nematode infections have not been definitively identified although it obviously plays a critical role in regulating responses mediated by eosinophils. IL-5 may also be necessary for normal development of the immune system, for example B-1 cell development. Although it is difficult to make direct comparisons, it appears that the exacerbation of nematode infections in IL-5-/-mice is much more severe than that in mice treated with neutralising monoclonal antibodies to IL-5. Since proposed treatments for asthma would inhibit the function of IL-5 rather than the development of the immune system, a better test of their effects on helminth infection would be to use mice given neutralising antibodies to IL-5 rather than mice genetically deficient in IL-5. Thus the outcomes of either $S$. ratti or $H$. polygyrus infection in IL-5-/- mice should be compared with those in normal mice given anti-IL-5 neutralising antibodies.

Even if short-term inhibition of IL-5 significantly exacerbates a number of helminth infections, treatment of asthmatics with inhibitors of IL-5 may still be a viable therapy. It could be argued that allergy and asthma affect human health in developed countries whereas helminth infections affect health in developing countries. But helminths in general, and intestinal nematodes in particular, are also prevalent in developed countries but are unnoticed or minor irritants as infection levels are low. Good hygiene reduces exposure to infective stages and immune responses in well-nourished people restrict adult worms to certain sites and limit their reproduction. There are, however, many examples of normally asymptomatic intestinal nematode infections becoming pathological. The pinworm Enterobius vermicularis is highly prevalent in developed countries, especially in children. Normally it is restricted to the gut and in light infections clinical symptoms are negligible (see Roberts \& Janovy 1996). Heavy infections, however, can be unbearable, causing irritability, inappetence, weight loss, insomnia and perianal pain. Very rarely this nematode penetrates the submucosa, a condition that can be fatal. S. stercoralis is another species that is not uncommon in developed countries. Its life cycle is similar to that of $S$. ratti. In immunosuppressed people the nematodes can disseminate throughout the body rather than remaining in the intestinal mucosa, with sometimes fatal consequences (Grove 1989, Wurtz et al. 1994). Both these species can cause autoinfection: eggs laid by intestinal worms can hatch in the gut or on the skin surrounding the anus, releasing larvae that then reinfect the same host. Therefore if IL-5 limits the sites occupied by and reproduction of these species, the infections could escalate to pathological levels if IL-5 is inhibited.

The methods by which IL-5 inhibitors are administered and the causal relationships between asthma and helminth infection will influence the effect that inhibition of IL-5 might have on helminth infections. For example, treatment of asthma by systemic inhibition of IL-5 could directly or indirectly exacerbate helminth infections, as outlined in the Figure. Thus, the results of systemic anti-IL-5 treatment could include exacerbation of helminth infections and either a decline in asthma 
symptoms or, if helminths indeed protect against asthma, exacerbation or less-effective attenuation of asthma symptoms. Whether more localised delivery of anti-IL-5 treatment to the lungs would affect helminth infections will depend on where IL-5-dependent anti-helminth mechanisms operate. In the case of $H$. polygyrus, IL-5-dependent immune responses must operate in the gut since all stages of this nematode are restricted to the gut. $S$. ratti, on the other hand, migrates extensively through the tissues, including the lungs. Although it is clear that IL-5-dependent immune responses reduce the number and reproductive success of $S$. ratti in the intestine, the parasite could be deleteriously affected before it reaches the gut. On balance, though, our results suggest that the anti-parasitic effects of IL-5 are predominantly mediated in the intestine. If this is so, local inhibition of IL-5 would only result in exacerbation of helminth infection if asthma protects against helminths.

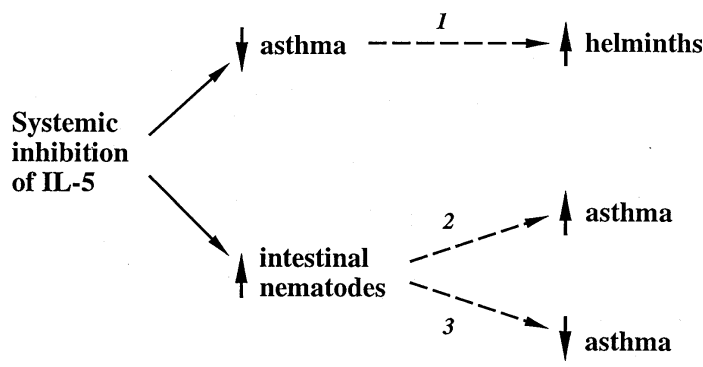

Possible consequences of systemic inhibition of IL-5: 1: assumes asthma protects against helminth infection by mechanisms independent of IL-5 (e.g. IgE, IL-4); 2: assumes helminth infection predisposes hosts to asthma by mechanisms independent of IL-5; 3: assumes helminth infection inhibits the development of asthma by mechanisms independent of IL-5.

In conclusion, our studies suggest that IL-5dependent immune responses are critically important in the control of intestinal nematode infections in mice. If this is also the case in humans, the viability of using inhibitors of IL- 5 as a therapy for asthma may be influenced by helminth infection. It is important to determine the characteristics of helminths that make them susceptible to IL-5-dependent immune responses. Any deleterious effects of some, but not all, species of helminth could effectively be limited by the concurrent use of anthelmintics: helminths that parasitise the gastrointestinal tract are in general cleared by anthelmintics, but some other species, such as tissue-dwelling S. stercoralis, filarial nematodes and Echinococcus (hydatid) larvae are less susceptible to anthelmintic therapy. Identification of the immunological mechanisms by which IL-5 limits helminth infection is of fundamental importance and may also influence the development of therapies for asthma.

\section{ACKNOWLEDGMENTS}

To Dr Elizabeth Milbourne for collaborating, many helpful discussion and her comments on the manuscript; Katherine McKie, Brendan McRandle, Debra Morgan all devoted students who carried out much of the experimental work discussed here; Dr Klaus Matthaei and Professor Ian Young for collaborating and providing the mice.

\section{REFERENCES}

Ackerman SJ, Kephart GM, Francis H, Awadzi K, Gleich GJ, Ottesen EA 1990. Eosinophil degranulation: an immunologic determinant in the pathogenesis of the Mazzotti Reaction in human onchocerciasis. $J$ Immunol 144: 3961-3969.

Beagley KW, Murray AM, Mcghee JR, Eldridge JH 1995. Peritoneal cavity CD5 (B1a) B cells: cytokine induced $\operatorname{IgA}$ secretion and homing to intestinal lamina propria in SCID mice. Immunol Cell Biol 73: 425-432.

Borrello MA, Phipps RP 1996. The B/macrophage cell - an elusive link between $\mathrm{CD}^{+} \mathrm{B}$ lymphocytes and macrophages. Immunol Today 17: 471-475.

Brattig NW, Tischendorf FW, Strote G, Medina de la Garza CE 1991. Eosinophil-larval-interaction in onchocerciasis: heterogeneity of in vitro adherence of eosinophils to infective third and fourth stage larvae and microfilariae of Onchocerca volvulus. Parasite Immunol 13: 13-22.

Bryant C 1982. The biochemical origins of helminth parasitism, p. 29-52. In LEA Symons, AD Donald, JK Dineen (eds), Biology and Control of Endoparasites. Academic Press, Sydney.

Burden DJ, Bland AP, Hammet NC, Hughes DL 1983. Fasciola hepatica: migration of newly excysted juveniles in resistant rats. Exp Parasitol 56: 277-288.

Butterworth AE, Dalton PR, Dunne DW, Mugambi M, Ouma JH, Richardson BA, Siongok TK, Sturrock RF 1984. Immunity after treatment of human Schistosomiasis mansoni. I. Study design, pretreatment observations and the results of treatment. Trans $R$ Soc Trop Med Hyg 78: 108-123.

Callahan HL, Crouch RK, James ER 1988. Helminth anti-oxidant enzymes: a protective mechanism against host oxidants? Parasitol Today 4: 218-225.

Charbon JL, Spahni M, Wicki P, Pfister K 1991. Cellular reactions in the small intestine of rats after infection with Fasciola hepatica. Parasitol Res 77: 425-429.

Chernin J, McLaren DJ 1983. The pathology induced in laboratory rats by metacestodes of Taenia crassiceps and Mesocestoides corti (Cestoda). Parasitology 87: 279-287.

Clemmey H 1976. World's oldest animal traces. Nature 261: 576.

Cook RM, Ashworth RF, Chernin J 1988. Cytotoxic activity of rat granulocytes against Mesocestoides corti. Parasite Immunol 10: 97-109.

Coyle AJ, Wagner K, Bertrand C, Tsuyuki S, Bews J, Heusser C 1996. Central role of immunoglobulin (Ig) 
$\mathrm{E}$ in the induction of lung eosinophil infiltration and $\mathrm{T}$ helper 2 cell cytokine production - inhibition by a non-anaphylactogenic anti-igE antibody. J Exp Med 183: 1303-1310.

Davies C, Goose J 1981. Killing of newly excysted juveniles of Fasciola hepatica in sensitized rats. Parasite Immunol 3: 81-96.

Dawkins HJ, Grove DI 1981. Kinetics of primary and secondary infections with Strongyloides ratti in mice. Int J Parasitol 11: 89-96.

Dawkins HJ, Thomason HJ, Grove DI 1982. The occurrence of Strongyloides ratti in the tissues of mice after percutaneous infection. J Helminthol 56: 45-50.

Dent LA, Strath M, Mellor AL, Sanderson CJ 1990. Eosinophilia in transgenic mice expressing interleukin 5. J Exp Med 172: 1425-1431.

Desreumaux P, Capron M 1996. Eosinophils in allergic reactions. Curr Opin Immunol 8: 790-795.

Doy TG, Hughes DL, Harness E 1980. The selective adherence of rat eosinophils to newly excysted Fasciola hepatica in vitro. Res Vet Sc 29: 98-101.

Folkard SG, Hogarth PJ, Taylor MJ, Bianco AE 1996. Eosinophils are the major effector cells of immunity to microfilariae in a mouse model of onchocerciasis. Parasitology 112: 323-329.

Foster PS, Hogan SP, Ramsay AJ, Matthaei KI, Young IG 1996. Interleukin 5 deficiency abolishes eosinophilia, airways hyperreactivity, and lung damage in a mouse asthma model. J Exp Med 183: 195-201.

Grove DI (Ed) 1989. Strongyloidiasis: a Major Roundworm Infection of Man. Taylor \& Francis, London, $336 \mathrm{pp}$.

Hagan P, Moore PJ, Adjukiewicz AB, Greenwood BM, Wilkins HA 1985a. In-vitro antibody-dependent killing of schistosomula of Schistosoma haematobium by human eosinophils. Parasite Immunol 7: 617-624.

Hagan P, Wilkins HA, Blumenthal UJ, Hayes RJ, Greenwood BM 1985b. Eosinophilia and resistance to Schistosoma haematobium in man. Parasite Immunol 7: 625-632.

Hardy RR, Hayakawa K 1986. Development and physiology of Ly-1 B and its human homolog, Leu-1 B. Immunol Rev 93: 53-79.

Haroun ET, Hillyer GV 1986. Resistance to fascioliasis - a review. Vet Parasitol 20: 63-93.

Herzenberg LA, Stall AM, Lalor PA, Sidman C, Moore WA, Parks DR, Herzenberg LA 1986. The Ly-1 B cell lineage. Immunol Rev 93: 81-102.

Hopkins CA, Subramanian G, Stallard H 1972. The development of Hymenolepis diminuta in primary and secondary infections in mice. Parasitology 64: 401412.

Johnson EH, Lustigman S, Brotman B, Browne J, Prince AM 1991. Onchocerca volvulus: in vitro killing of microfilaria by neutrophils and eosinophils from experimentally infected chimpanzees. Trop Med Parasitol 42: 351-355.

Jones DG 1993. The eosinophil. J Comp Pathol 108: 317-335.

Kayes SG, Oaks JA 1980. Toxocara canis: T lymphocyte function in murine visceral larva migrans and eosinophilia onset. Exp Parasitol 49: 47-55.
Keymer A 1982. Density-dependent mechanisms in the regulation of intestinal helminth populations. Parasitology 84: 573-587.

Konno S, Gonokami Y, Kurokawa M, Kawazu K, Asano K, Okamoto K, Adachi M 1996. Cytokine concentrations in sputum of asthmatic patients. Int Arch Allergy Immunol 109: 73-78.

Kopf M, Brombacher F, Hodgkin P, Ramsay AJ, Milbourne EA, Dai WJ, Ovington KS, Behm CA, Köhler G, Young IG, Matthaei KI 1996. IL-5 deficient mice have a developmental defect in $\mathrm{CD}^{+} \mathrm{B}-1$ cells and lack eosinophilia but have normal antibody and cytotoxic T cell responses. Immunity 4: 15-24.

Korenaga M, Hitoshi Y, Takatsu K, Tada I 1994. Regulatory effect of anti-interleukin-5 monoclonal antibody on intestinal worm burden in a primary infection with Strongyloides venezuelensis in mice. Int J Parasitol 24: 951-957.

Korenaga M, Hitoshi Y, Takatsu K, Tada I 1995. Crossresistance between Strongyloides venezuelensis and $S$. ratti in mice. J Helminthol 69: 119-123.

Korenaga M, Hitoshi Y, Yamaguchi N, Sato Y, Takatsu K, Tada I 1991. The role of interleukin-5 in protective immunity to Strongyloides venezuelensis infection in mice. Immunology 72: 502-507.

Kusama Y, Takamoto M, Kasahara T, Takatsu K, Nariuchi H, Sugane K 1995. Mechanisms of eosinophilia in BALB/c-nu/+ and congenitally athymic BALB/c-nu/nu mice infected with Toxocara canis. Immunology 84: 461-468.

Lange AM, Yutanawiboonchai W, Scott P, Abraham D 1994. IL-4- and IL-5-dependent protective immunity to Onchocerca volvulus infective larvae in BALB/cBYJ mice. J Immunol 153: 205-211.

Martin LB, Kita H, Leiferman KM, Gleich GJ 1996. Eosinophils in allergy - role in disease, degranulation, and cytokines. Int Arch Allergy Immunol 109: 207-215.

Medina de la Garza CE, Brattig NW, Tischendorf FW, Jarrett JM 1990. Serum-dependent interaction of granulocytes with Onchocerca volvulus microfilariae in generalized and chronic hyper-reactive onchocerciasis and its modulation by diethylcarbamazine. Trans $R$ Soc Trop Med Hyg 84: 701-706.

Milbourne EA, Howell MJ 1990. Eosinophil responses to Fasciola hepatica in rodents. Int J Parasitol 20: 705-708.

Milbourne EA, Howell MJ 1993. Eosinophil differentiation in response to Fasciola hepatica and its excretory secretory antigens. Int J Parasitol 23: 10051009.

Milbourne EA, Howell MJ 1997. Eosinophilia in nude rats and nude mice after infection with Fasciola hepatica or injection with its $\mathrm{E} / \mathrm{S}$ antigens. Int $J$ Parasitol 27: 1099-1105.

Monroy FG, Enriquez FJ 1992. Heligmosomoides polygyrus: a model for chronic gastrointestinal helminthiasis. Parasitol Today 8: 49-54.

Moqbel R 1980. Histopathological changes in rats following primary, secondary and repeated infections with Strongyloides ratti, with special reference to tissue eosinophils. Parasite Immunol 2: 11-27. 
Moqbel R, Denham DA 1977. Strongyloides ratti: 1. Parasitological observations on primary and secondary infections in the small intestine of rats. $J$ Helminthol 51: 301-308.

Murakami M, Honjo T 1995. Involvement of B-1 cells in mucosal immunity and autoimmunity. Immunol Today 16: 534-539.

Pollacco S, Nicholas WL, Mitchell GF, Stewart AC 1978. T-cell dependent collagenous encapsulating response in the mouse liver to Mesocestoides corti (Cestoda). Int J Parasitol 8: 457-462.

Pritchard DI 1992. Parasites and allergic disease: a review of the field and experimental evidence for a 'cause and effect' relationship, p. 38-50. In R Moqbel, Allergy and Immunity to Helminths: Common Mechanisms or Divergent Pathways? Taylor \& Francis, London.

Read CP 1967. Longevity of the tapeworm, Hymenolepis diminuta. J Parasitol 53: 1055-1056.

Roberts LS, Janovy J 1996. Foundations of Parasitology. W.C. Brown, Dubuque, 659 pp.

Robinson DS, Hamid Q, Ying S, Tsicopoulos A, Barkans J, Bentley AM, Corrigan C, Durham SR, Kay AB 1992. Predominant TH2-like bronchoalveolar Tlymphocyte population in atopic asthma. $N$ Engl $J$ Med 326: 298-304.

Sanderson CJ 1991. Control of eosinophilia. Int Arch Allergy Immunol 94: 122-126.

Sanderson CJ 1992. Interleukin-5, eosinophils, and disease. Blood 79: 3101-3109.

Sanderson CJ 1994. Interleukin-5, p. 127-144. In AW Thomson, The Cytokine Handbook. Academic Press, London.

Sasaki O, Sugaya H, Ishida K, Yoshimura K 1993. Ablation of eosinophils with anti-IL-5 antibody enhances the survival of intracranial worms of Angiostrongylus cantonensis in the mouse. Parasite Immunol 15: 349-354.

Smith NC, Ovington KS, Boray JC 1992. Fasciola hepatica: free radical generation by peritoneal leukocytes in challenged rodents. Int J Parasitol 22: 281286.

Specht D, Voge M 1965. Asexual multiplication of Mesocestoides tetrathyridia in laboratory animals. $J$ Parasitol 51: 268-272.

Sturrock RF, Kimani R, Cottrell BJ, Butterworth AE, Seitz HM, Siongok TK, Houba V 1983. Observations on possible immunity to reinfection among Kenyan schoolchildren after treatment for Schistosoma mansoni. Trans R Soc Trop Med Hyg 77: 363-371.
Sugane K, Oshima T 1980. Recovery of large numbers of eosinophils from mice infected with Toxocara canis. Am J Trop Med Hyg 29: 799-802.

Sugane K, Oshima T 1982. Eosinophilia, granuloma formation and migratory behaviour of larvae in the congenitally athymic mouse infected with Toxocara canis. Parasite Immunol 4: 307-318.

Svetic A, Madden KB, Zhou XD, Lu P, Katona IM, Finkelman FD, Urban JF, Gause WC 1993. A primary intestinal helminthic infection rapidly induces a gut-associated elevation of Th2-associated cytokines and IL-3. J Immunol 150: 3434-3441.

Tagboto SK 1995. Interleukin-5, eosinophils and the control of helminth infections in man and laboratory animals. J Helminthol 69: 271-278.

Takamoto M, Kusama Y, Takatsu K, Nariuchi H, Sugane K 1995 . Occurrence of interleukin-5 production by $\mathrm{CD}^{-}{ }^{-} \mathrm{CD}^{-}$(double-negative) $\mathrm{T}$ cells in lungs of both normal and congenitally athymic nude mice infected with Toxocara canis. Immunology 85: 285-291.

Takamoto M, Ovington KS, Behm CA, Sugane K, Young IG, Matthaei KI 1997. Eosinophilia, parasite burden and lung damage in Toxocara canis infection in C57B1/6 mice genetically deficient in IL-5. Immunology 90: 511-517.

Tominaga A, Takaki S, Koyama N, Katoh S, Matsumoto R, Migita M, Hitoshi Y, Hosoya Y, Yamauchi S, Kanai Y, Miyazaki J-I, Usuku G, Yamamura K-I, Takatsu K 1991. Transgenic mice expressing a B cell growth and differentiation factor gene (interleukin 5) develop eosinophilia and autoantibody production. $J$ Exp Med 173: 429-437.

Urban JF, Katona IM, Paul WE, Finkelman FD 1991. Interleukin-4 is important in protective immunity to a gastrointestinal nematode infection in mice. Proc Nat Acad Sci USA 88: 5513-5517.

Wardlaw AJ, Moqbel R 1992. The eosinophil in allergic and helminth-related inflammatory responses, $\mathrm{p}$. 154-186. In R Moqbel, Allergy and Immunity to Helminths: Common Mechanisms or Divergent Pathways? Taylor \& Francis, London.

Wurtz R, Mirot M, Fronda G, Peters C, Kocka F 1994. Short report - gastric infection by Strongyloides stercoralis. Am J Trop Med Hyg 51: 339-340.

Yoshida T, Ikuta K, Sugaya H, Maki K, Takagi M, Kanazawa H, Sunaga S, Kinashi T, Yoshimura K, Miyazaki J, Takaki S, Takatsu K 1996. Defective B1 cell development and impaired immunity against Angiostrongylus cantonensis in IL-5R $\alpha$-deficient mice. Immunity 4: 483-494. 